\title{
Design, Modernidade Industrial e Colecionismo
}

Fernanda Sabrina Finardi;

Richard Perassi Luiz de Sousa

resumo:

Este artigo apresenta parte de uma pesquisa qualitativa sobre o tema produtos de Design na cultura do colecionismo. A pesquisa, realizada com (1) uma etapa exploratória para buscar fontes e (2) outra etapa bibliográfica para identificar e selecionar conceitos, arranjos teóricos e informações sobre o tema, tem como objetivo geral evidenciar a influência cultural dos produtos industriais como motivação ao colecionismo. Tal fenômeno decorre do domínio estético-simbólico do Design na convivência cotidiana de várias gerações de pessoas nos séculos XX e XXI. A relevância cultural dos produtos industriais ganha ênfase nas coleções de produtos aparentemente "banais" e de baixo custo, pois além de seus aspectos sócio-históricos também são consideradas as motivações subjetivas, intersubjetivas e socioculturais no contexto da cultura moderna ocidental. Sintetizando: o principal resultado da pesquisa é assinalar que o valor simbólico-social dos produtos industriais, principalmente dos aparentemente "banais", é diretamente associado às qualidades formais e funcionais definidas nos projetos de Design, como é especialmente destacado no colecionismo.

\section{palavras-chave:}

Coleção de Produtos; Sociedade de Mercado; Cultura Industrial 


\section{Introdução}

O colecionismo de produtos é um tema amplo, porque a significação de "produto" também é ampla, sendo considerada em diferentes aspectos. Atualmente, a palavra "produto" pode nomear tudo que é criado ou fabricado, seja pela natureza ou por atividade humana. Mas, de maneira mais específica e interessante, a palavra "produto" também é usada para designar um bem de comércio ou consumo, como um sinônimo de "mercadoria". Aliás, o produto como mercadoria e, também, como peça de coleção são duas condições privilegiadas neste artigo. Neste texto, é indicado que o interesse pelo colecionismo na moderna cultura ocidental ocorreu inicialmente no contexto histórico-econômico mercantilista, entre os séculos XV e XVIII. Isso foi devido ao interesse europeu sobre o conhecimento, especialmente, dos bens naturais e dos artefatos encontrados, explorados e comercializados, na ampla expansão da navegação marítima.

Na sequência, a ênfase na exploração e no comércio de produtos já existentes foi sendo constantemente substituída pela criação formal, com projetos de Design, e a fabricação em série de produtos industrializados, sendo essa dinâmica e seus resultados que caracterizaram a sociedade industrial do século XX. Mas, na segunda metade do mesmo século, a "indústria cultural" emergiu e foi continuamente desenvolvida, assinalando, valorizando e precificando os aspectos estéticosimbólicos dos produtos industriais. Isso inaugurou o culto intersubjetivo ao produto industrial que, anteriormente, era quase exclusivamente dedicado às obras literárias e artísticas.

O colecionismo de objetos aparentemente "banais", constantemente, é alimentado pelo culto aos produtos industriais. Isso é constituído no jogo histórico-comercial entre o excesso e a falta. Por exemplo, em um certo período há a oferta excessiva do produto, o qual invade por anos o cotidiano familiar das pessoas. Mas, em seguida, o mesmo produto é substituído por outro ou por sua versão mais "moderna", com mudanças na formulação ou na embalagem. Depois de algum tempo, ocorre a escassez do produto, deixando um excesso de lembranças do tempo de convívio com sua realidade. Assim, como registro afetivo do tempo vivido, os exemplares remanescentes de um produto passam a ser cultuados e colecionados, como registros estético-simbólicos do período memorável que ainda representam.

Além de ressaltar e precificar os aspectos estético-simbólicos dos bens materiais de uso ou consumo, com a "indústria cultural" também houve a ampla valorização dos produtos de comunicação, como livros, revistas ilustradas, histórias em quadrinhos (gibis), jogos de tabuleiro, filmes e animações, entre outros. Tudo isso foi ainda mais desmaterializado, divulgado e comercializado nesta era digital, que marca o século XXI. A comunicação digital é sustentada pela tecnologia eletrônica de aparatos materiais, mas o conteúdo estético-simbólico, que é amplamente comunicado em rede online, predomina em importância e caracteriza esta cultura como pós-industrial. Muitos heróis, heroínas e outras celebridades e personagens que povoam a cibercultura são remanescentes ou fazem referências às figuras ou aos produtos do passado. Portanto, houve a superação da cultura industrial, mas atualmente a "indústria cultural" ainda permanece e manifesta seu apogeu.

No contexto dos acervos institucionais, a história ocidental do colecionismo é relacionada ao desenvolvimento do conhecimento científico, reunindo acervos de peças naturais e artefatos, como registros histórico-geográficos de diferentes culturas. Sobre a participação de Design e designers, destaca-se o desenvolvimento da área e sua contínua consolidação, como campo de atividades e estudos, mais especificamente, a partir da consolidação da revolução industrial.

Observa-se que já nas primeiras décadas do século XX, os designers foram formalmente habilitados a criar e projetar produtos passíveis de serem industrialmente fabricados (desenho industrial). Isso foi especialmente destacado na pedagogia em Design (WICK, 1989), desenvolvida na escola alemã Bauhaus (1919-1933). A atuação dos designers passou a orientar o trabalho de equipes manufatureiras, máquinas e sistemas conjugados de trabalhadores e máquinas encarregados da fabricação industrial seriada. 
Em síntese, as atividades de colecionismo estiveram relacionadas ao comércio e ao conhecimento ocidental que, entre outras possibilidades, desenvolveu os recursos técnico-científicos que prepararam e provocaram a revolução industrial e suas amplas consequências socioculturais. Por sua vez, de maneira mais ou menos formal, a área de Design projetou toda a estrutura produtiva e os produtos da cultura industrial que, em seguida, passaram também a ser conservados e cultuados nas atividades de colecionismo.

Tópicos do percurso ocidental do colecionismo, enfatizando sua relação com a cultura industrial, a área de Design e a "indústria cultural", principalmente nas coleções de produtos industriais aparentemente "banais", caracterizam o estudo apresentado neste artigo. Isso é resultado de uma pesquisa qualitativa, cujas informações coletadas e descritas decorreram principalmente de estudos bibliográficos. As fontes de pesquisa predominantemente bibliográficas e algumas documentais, previamente, foram identificadas e selecionadas em uma etapa exploratória. Mattar (2005, p. 81) assinala as oportunidades de se obter "maior conhecimento sobre um tema, desenvolver hipóteses para serem testadas e aprofundar questões a serem estudadas". Além da etapa exploratória, na pesquisa qualitativa também houve estudos bibliográficos e documentais, sem a interferência no registro dos dados coletados, apesar da proposição de comparações e interpretações coerentes com a teoria aplicada no estudo (VALENTIM, 2005).

\section{Aspectos lógico-objetivos: colecionismo e conhecimento moderno}

Juntamente com as primeiras manifestações mais formalizadas de artesania, que caracterizariam a mais distante ancestralidade das atividades de Design, emerge também a atenção ao colecionismo de coisas da natureza ou da produção cultural, reunindo objetos com certo grau de sofisticação, assinalando seu caráter de Design no sentido de projeto utilitário de artefato estético. Para Andreozi (2020), o colecionismo assim proposto surgiu de maneira rudimentar com a produção dos instrumentos primitivos desenvolvidos pela espécie homo habilis, já nas primeiras comunidades fixas. Portanto, houve uma evolução crescente, perpassando todos os períodos da pré-história. Por sua vez, Pomian (1984) informa que, na antiguidade greco-romana, houve personalidades como Aristóteles e Plínio, entre outras, que já colecionavam coisas, compondo coleções ou acervos, cujo formato influenciou a prática do colecionismo e definiu um estilo de coleção que prevaleceu até os séculos XVI e XVII.

Sobre o colecionismo na época mercantilista, a partir do século XV, Le Goff (1990) informa que, no contexto renascentista e até o final do século XVIII, houve a revalorização do passado. Principalmente, foi valorizado o que era relacionado ao humanismo e à racionalidade da antiguidade greco-romana, considerada a idade do ouro, com o florescimento da cultura ocidental, acentuando o interesse europeu por objetos desse passado glorioso.

A partir do momento renascentista, devido às navegações e suas descobertas, também houve a ampliação do conhecimento territorial e o aumento do interesse por estudos naturais. Isso influiu decisivamente no hábito de reunir coisas ou objetos, formando coleções que, entre outras possibilidades, também denotavam status social. Inclusive, foi consolidado o interesse por artefatos exóticos, objetos artísticos e curiosos, principalmente os trazidos das viagens distantes de descobridores e comerciantes. A efervescência artística e cultural caracterizou o período entre os séculos XVI e XVIII, provocando a busca por erudição e a organização do conhecimento. Os esforços da época foram consolidados no Iluminismo, como movimento político-cultural, cuja ilustração culminou no projeto enciclopedista.

Em síntese, o crescente interesse por colecionar raridades de lugares distantes incrementou o colecionismo entre os nobres europeus que, para guardar as peças de coleção, providenciaram a feitura de armários ricamente diferenciados e denominados de "gabinetes de curiosidades" (RAFFAINI, 1993). Do mesmo modo que ostentar posses e riquezas, incluindo joias, peças de vestuário, livros e obras de arte, Raffaini (1993) considera que, na época, dispor de gabinetes de curiosidades era sinal de 
sucesso financeiro, prestígio social e requinte pessoal. Isso porque assinalavam gostos, interesses e recursos diferenciados, indicando o maior grau de instrução e a atualidade dos proprietários.

Houve a consolidação e a ampliação da prática do colecionismo e seu compartilhamento social. Pomian (1983) assegura que existiam inúmeros gabinetes de curiosidades espalhados no contexto europeu, cujos donos eram nobres, artistas ou ricos burgueses como, por exemplo: a Família Médici, o Imperador Rodolfo em Praga, o Arquiduque Ferdinando em Viena, o Duque Alberto V da Baviera e o médico Pierre Borel. Nas coleções da época, a variedade predominava sobre a homogeneidade. Assim, pedras, plantas, restos de animais e artefatos culturais podiam ocupar um mesmo gabinete. Na época, os móveis produzidos e usados como gabinetes, comumente, eram artigos de luxo, sendo confeccionados com os mais ricos materiais por exímios artesãos (Figura 1).

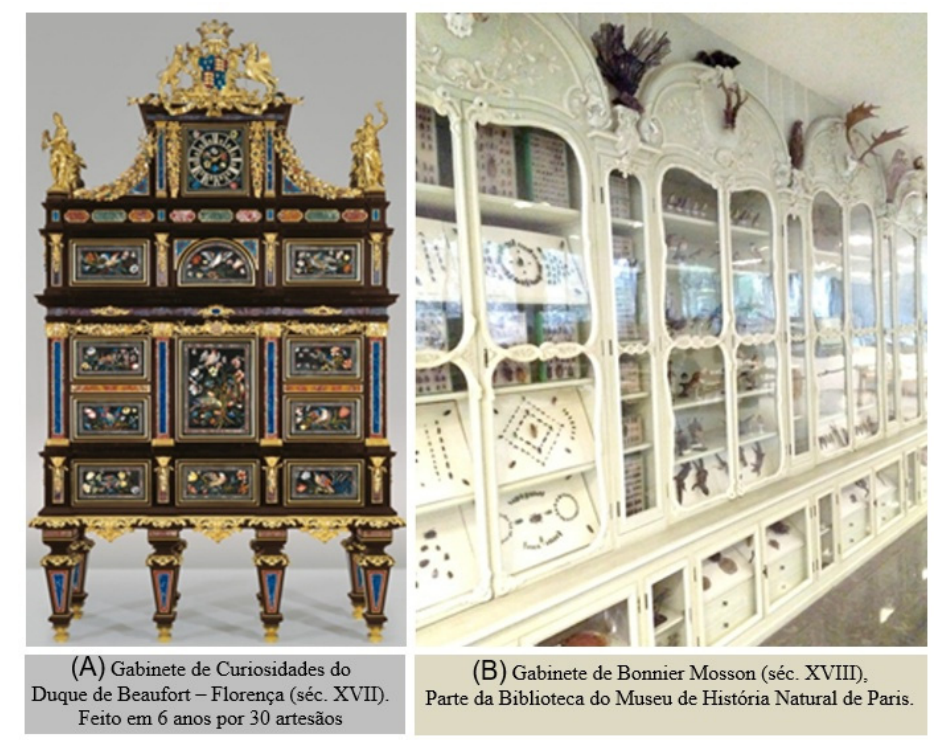

Figura 1. Gabinetes de Curiosidades dos séculos XVII (A) e XVIII (B)

Fontes das imagens: https://wherefivevalleysmeet.blogspot.com/2012/11/the-decorative-art-of-pietradura.html - http://marimerveille.canalblog.com/archives/2018/02/08/36113343.html

As figuras acima (1A e 1B) exemplificam os gabinetes de curiosidades onde eram guardadas peças raras e exóticas de lugares distantes cujo luxo e maestria artesanal definiam seu estilo. Tudo isso denotava também os gostos dos proprietários, configurando o conjunto de móveis e peças como o arranjo particular de suas preferências. Os gabinetes de curiosidades serviram de embrião e fonte de oferta de peças para a configuração dos museus de História Natural e, sequencialmente, de outros museus históricos, artísticos ou científicos e técnicos, de diferentes especialidades ou áreas de interesse. Em constante desenvolvimento, isso constituiu o amplo e diversificado patrimônio estabelecendo o campo de estudo de áreas como Museologia e Museografia.

Em síntese, a relação entre colecionismo e modernidade técnico-científica, primeiramente, decorreu da dinâmica mercantilista e da consolidação do pensamento lógico-racional. De modo mais ou menos criterioso houve a disseminação da prática do colecionismo, visando identificar, reunir e organizar a fabricação humana e a produção natural. Para Camargo (2012), o colecionismo respondeu ao desejo de se constituir um microcosmos (como miniatura de universo), que poderia ser mensurado, racionalmente controlado e dominado como sistema político-econômico.

\section{Aspectos históricos e subjetividade: colecionismo e memória}

Os valores socioculturais de uma época deixam resquícios para a posteridade, os quais são influenciam os comportamentos das gerações posteriores. Assim, pode-se considerar que a origem nobre do colecionismo moderno ocidental deixou como herança a ideia generalizada de sofisticação no ato de 
colecionar. Além disso, de maneira mais ou menos evidente e com maior ou menor detalhamento, todo corpo material memoriza ou registra seu processo de constituição e afetos ou efeitos decorrentes das ações posteriores de outros agentes físicos, materiais ou energéticos (PERASSI, 2019).

Como corpos de registro, as peças de uma coleção expressam afetos já ocorridos e, por isso, são observados como objetos memorativos. Em síntese, selecionar e colecionar objetos é acumular registros ou memórias de acontecimentos passados, cujo valor pode ser pessoal ou coletivo, com relação ao histórico de nações, sociedades, comunidades, famílias e pessoas. Individualmente ou em conjunto, os objetos selecionados como peças de uma coleção são legados históricos e expressam valores estético-simbólicos do seu contexto de produção e conservação ao longo do tempo.

Os corpos das peças colecionadas também afetam os sensores fisiológicos e as mentes das pessoas. Assim, por razões culturais ou particulares, colecionadores e colecionadoras reúnem peças sob critérios específicos de organização e guarda. Em decorrência disso, acervos são organizados e ampliados, de modo mais ou menos formal. Alguns são criteriosamente catalogados, de acordo com padrões institucionalmente constituídos. Mas outros são simplesmente arranjados conforme os interesses pessoais ou subjetivos de colecionadores e colecionadoras.

Como foi apresentado, no colecionismo europeu dos séculos XVI, XVII e XVIII, havia o interesse pelo passado na antiguidade. Mas o interesse ainda maior foi direcionado aos registros distantes no espaço geográfico, implicando as diferenças étnico-raciais e o exotismo de coisas e produtos diversos do cenário europeu. Interessavam o conhecimento e a atuação político-econômica sobre a realidade ampliada para além dos limites do território europeu. Isso influenciou a consequente consolidação da cultura colecionista em museus e outras instituições de conservação memorativa e histórico-geográfica.

Além dos acervos institucionais formados em função do interesse acadêmico-científico e histórico-geográfico, também, há diversas outras coleções decorrentes de motivações particulares e subjetivas de colecionadores ou colecionadoras. No contexto sociopsicológico, são indicadas motivações interativas entre aspectos sociais e subjetivos. Por exemplo, escapismo, nostalgia, saudosismo, status, poder de posse, hedonismo, encantamento estético e apelo à imortalidade. Isso porque a preservação e o cuidado com as peças da coleção propõem ainda a perpetuação da identidade da pessoa que coleciona.

O colecionismo com motivação hedonista resulta na acumulação mais ou menos organizada de elementos, sob motivações subjetivas, criativo-afetivas, sugerindo o caráter poético da atividade. Assim, os resultados potencialmente positivos e compensatórios tornam a prática estimulante ou apaixonante. Hargreaves $(2014$, p. 2) confirma que isso "é relatado por vários colecionadores, que associam ao ato de investigar e pesquisar esse tom poético e até romântico, contribuindo para o seu prazer e felicidade". Inclusive, a aquisição da peça desejada "pode adquirir contornos de obsessão, sendo este indubitavelmente o grande trunfo dos leilões".

Em síntese, o estímulo, a paixão, a compulsão e as características psíquico-subjetivas justificam a disposição das pessoas em colecionar quaisquer tipos de coisas. Aliás, isso inclui o colecionismo de produtos industriais aparentemente "banais", envolvendo aspectos subjetivo-afetivos diretamente relacionados às características estético-simbólicas e socioculturais das peças selecionadas e colecionadas. Subjetivamente, no colecionismo de produtos industrializados, reconsidera-se a ideia de "aura", como característica dos objetos únicos, observada nas obras de arte tradicionais.

No texto clássico de 1936, "A obra de arte na era de sua reprodutibilidade técnica", Walter Benjamin advertiu que a serialização dos objetos, principalmente das obras de arte, os destituiria de sua "aura" de autenticidade e unicidade. Para o autor, "o aqui e agora do original constitui o conteúdo da sua autenticidade, e nela se enraíza uma tradição que identifica esse objeto, até os nossos dias, como sendo aquele objeto, sempre igual e idêntico a si mesmo" (BENJAMIN, 1980, p. 167). Mas a reconsideração parte da ideia de que qualquer cópia de uma série é uma reprodução que, em grande 
parte, perpetua as características do original. Assim, quando as cópias de um mesmo original são observadas em grupo não há distinção identitária entre essas, mas na coleção de um tipo específico de produto, por exemplo na de automóveis, cada produto colecionado pode ser de um fabricante distinto ou de edições únicas, como as que ocorreram no histórico de fabricação do automóvel Volkswagen (Figura 2).

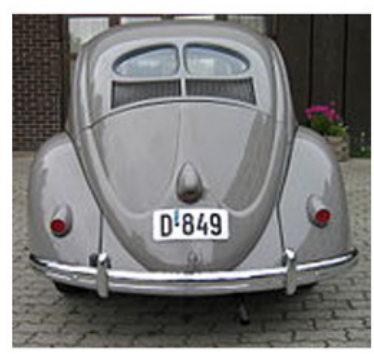

A icônica janela bipartida, introduzida em 1938.

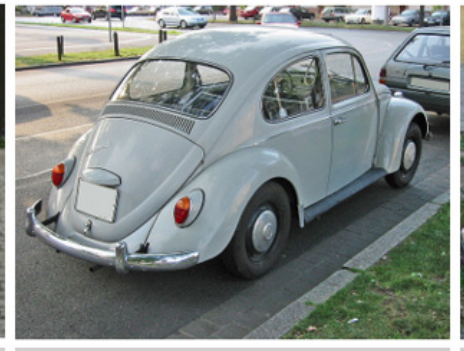

Em 1962, novas lanternas traseiras.
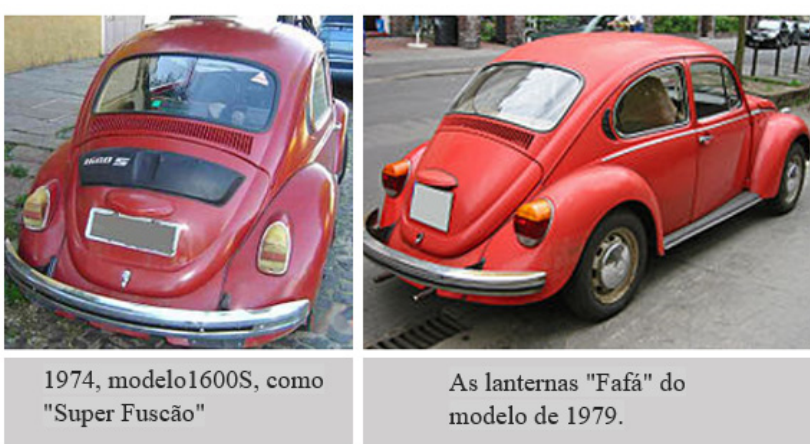

Figura 2. Edições de anos diferentes do automóvel Volkswagen (Fusca).

Fonte das imagens: https://pt.wikipedia.org/wiki/Volkswagen Fusca

$\mathrm{Na}$ coleção, além de representar o modelo original e o seu contexto sócio-histórico, as particularidades no "desenho" de cada peça, a distingue estético e simbolicamente das outras, sendo assim percebida como única no conjunto. Isso the confere uma "aura" específica no conjunto, definindo um éthos especial que, estética e simbolicamente, contamina e informa o observador. Essa possibilidade também mobiliza o desejo e encanta colecionadores e colecionadoras, por seu poder de modificar o status do produto seriado, alçando-o à condição de peça única e significativa.

Por falta de interesse ou condições "nem todas as coleções são conhecidas. Existem aquelas que permanecem no anonimato constituindo uma chama lenta e ardente dentro da alma do colecionador" (HARGREAVES, 2014, p. 6). Ainda sobre o encantamento das pessoas que colecionam, Benjamin (2009, p. 239) também propõe que "tudo o que é lembrado, pensado, consciente, torna-se suporte, pedestal, moldura, fecho de sua posse". Conscientemente, "colecionar é uma forma de recordação prática", como ambiente imaginário de invenções e lembranças, que incita e sustenta o culto aos objetos.

Inicialmente, os objetos fabricados em série e comercializados em massa foram e são banalizados ou desprezados por sua redundante presença no contexto social. Mas como foi evidenciado no pensamento Andy Warhol (2008) e nas suas obras de PopArt, a constância dos produtos no cotidiano das famílias marca a vida das pessoas. Muitas vezes, a convivência direta ou indireta com produtos específicos pode persistir durante décadas ou até mesmo perdurar por toda a vida. $\mathrm{O}$ ato de consumir regularmente um produto industrializado e descartar sua embalagem propõe momentos de presença e ausência material do produto e seus vestígios. Porém, a recorrência dessa prática resulta na consolidação de uma constante marca mental relacionada ao produto e a tudo que lhe é associado.

A marca mental é composta por lembranças de sensações e afetos, evocando sentimentos, emoções e ideias vinculadas às experiências com o produto. Isso implica os momentos de aquisição e uso ou consumo, incluindo até a simples presença do produto em certas circunstâncias. Por exemplo, a canção "Mamãe", dos compositores David Nasser e Herivelto Martins, (muito popular nos anos 1950) continha em sua letra os seguintes versos: "Mamãe, mamãe, mamãe". "Eu te lembro o chinelo na mão". "O avental todo sujo de ovo". Na lembrança relatada são citados diferentes produtos: "chinelo", "avental", "ovo", que foram selecionados, colecionados e publicados na letra da canção, como marcas de uma existência vivida ou imaginada, com forte sentido emocional. 


\section{Aspectos socioculturais: colecionismo e Indústria Cultural}

Como todo artefato produzido e aprimorado pelo homem, os objetos criados por designers e produzidos em escala industrial, também, acabam despertando o interesse dos colecionadores. Cada objeto industrial com sua função e forma é um recorte estético-simbólico do momento sócio-histórico de sua criação e utilização habitual por pessoas, revelando o padrão cultural de uso ou consumo e, consequentemente, um modo de vida. Assim, há produtos de todos os tipos que são selecionados e integrados como peças de uma coleção: bonés, bibelôs, botons, canecas, chaveiros, chaves, cinzeiros, canetas, gravuras, bonecos, cédulas, moedas, selos (Figura 3), embalagens, miniaturas, flâmulas, vestuário, mobiliário, automóveis, filmes, cartões postais, câmeras fotográficas e outros.

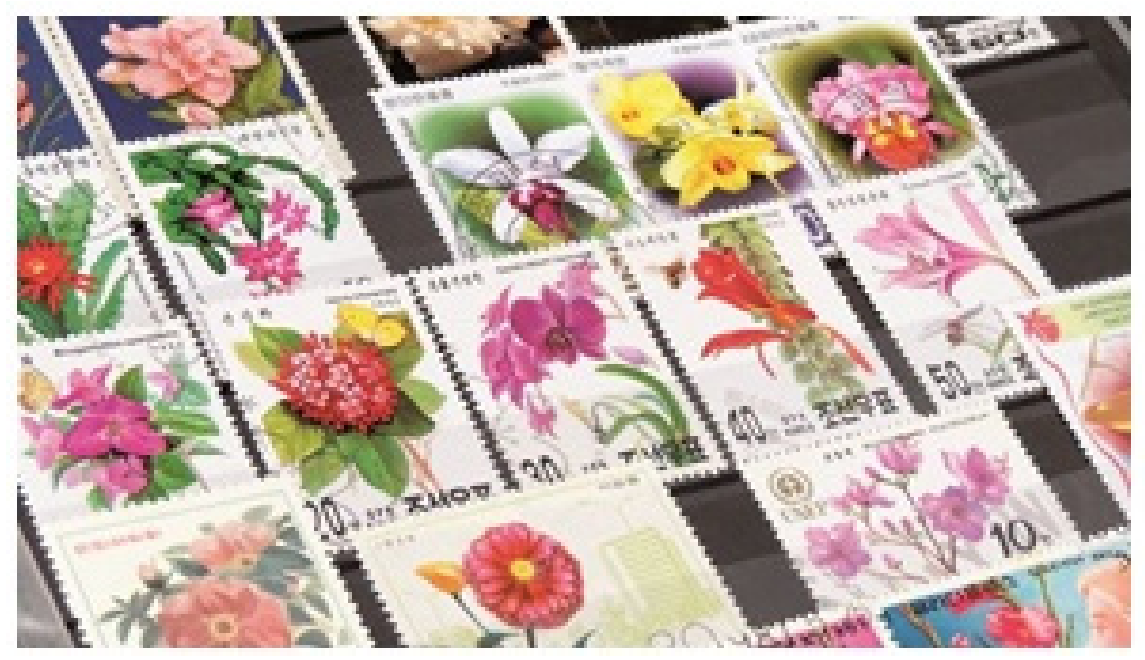

Figura 3. Parte de uma coleção de selos postais

Fonte: https://omunicipio.com.br/conheca-a-filatelia-habito-de-colecionar-e-pesquisar-selos-postais/

Nas primeiras décadas do século XX, ocorreu o desenvolvimento acelerado da cultura industrial, sendo demarcado com a hegemonia da produção em massa de produtos fabricados em série e grande escala. Inclusive, também como consequência da massiva comunicação publicitária, houve ampla popularização do consumo de produtos industrializados. Aliás, a parte ideológica da cultura industrial, produzida no contexto da comunicação publicitária, também foi divulgada em grande escala na mídia de massa. As amplas lojas de departamentos, cujo início ocorrera ainda no final do século XIX, prosperaram no século XX como "templos" ocidentais do consumo (CHANEY, 1983). Atualmente, as lojas de departamento foram praticamente extintas ou reformatadas. Mas, ainda persiste a popularização de super e hipermercados, shopping-centers e lojas ou feiras populares de produtos industrializados, havendo também a franca expansão de e-commerce.

Primeiramente, a justificativa para o investimento sociopolítico e econômico no progresso da indústria foi a ampliação do acesso público aos bens utilitários. Por exemplo, no artigo, "Coleções: passatempo ou obsessão?", publicado no magazine Super Interessante, Narloch (2004) assinala que, anteriormente à indústria, a aquisição de um copo de vidro era restrita a privilegiados que podiam pagar pelo produto. Mas, no contexto do colecionismo nos séculos XX e XXI, o mesmo autor comenta que a expansão e a diversificação da produção industrial de produtos de baixo custo passaram a "oferecer bugigangas coloridinhas, engraçadinhas, fofinhas" (Figura 4) para serem colecionadas. "Se a bugiganga for produzida em edições limitadas, como cartões telefônicos, cairá no gosto de colecionadores facilmente." (NARLOCH, 2004, p. s/n). 


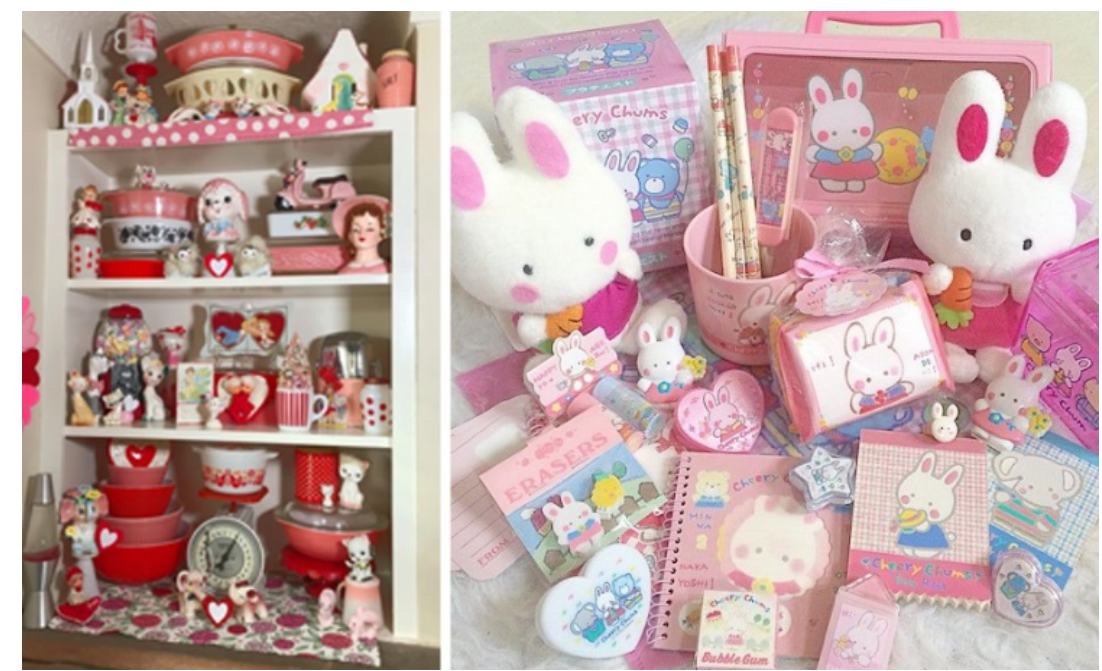

Figura 4. Produtos industriais coloridos e infantilizados

Fontes das imagens: https://www.reddit.com/r/kitsch/comments/eqq1 $1 \mathrm{pm} / \mathrm{kitsch}$ pyrex_valentines_decor/ https://br.pinterest.com/pin/838865868067609433/

A compra com ágio e o colecionismo de "bugigangas" e outros produtos industriais banais, devido à apreciação de suas características estético-simbólicas, evidenciam uma outra instituição socioeconômica designada "Indústria Cultural". Apesar das críticas contundentes de Horkheimer e Adorno (2002), entre outros autores frankfurtianos da década de 1920, os produtos industriais foram continuamente percebidos, admirados e colecionados como objetos estético-simbólicos e registros sócio-históricos. Os exemplos notáveis são as coleções de selos, notas e moedas, cujo caráter histórico-documental é inegável. Mas, na dinâmica da indústria cultural, a função prática dos produtos é secundarizada e o consumo é prioritariamente influenciado por seus aspectos estético-simbólicos ou ideológicos. Em síntese, já nas primeiras décadas do século XX, a prioridade da produção e do consumo de grande parte dos produtos industriais foi deslocada da funcionalidade para a potencialidade estético-simbólica. Isso foi realizado com o consórcio da comunicação publicitária na mídia de massa, redirecionando o interesse social para a linguagem dos produtos industriais, incluindo os banais, de baixo custo e pouco valor.

No texto "A Linguagem das Coisas", Deyan Sudjic (2010) retoma a construção simbólicodiscursiva dos produtos industriais, incluindo aspectos relacionados com Design, Comunicação e Moda. A hipertrofia sensório-afetiva e simbólica dos produtos foi diretamente influenciada pela comunicação publicitária, que aguça o interesse público ressaltando aspectos estruturais e contextuais. Assim, o que não pode ser diretamente percebido é comunicado ao público, com informações sobre "as complexidades das séries, procedência e linhagem dos modelos". O conjunto de informações complementares compõe a marca mental. Isso ocorre com a associação de sensações e imaginações e extasiam a percepção, "que transforma em fetiche óculos de sol e canetas tinteiro, sapatos e bicicletas e quase tudo que possa ser colecionado, categorizado, organizado e, em última análise, possuído" (SUDJIC, 2010, p. 6)

A comunicação pública e publicitária dos fabricantes, dos distribuidores ou dos que comercializam os produtos é basicamente controlada por gestores de Marketing que, em interação com outros administradores e executores, definem estratégias e ações de relacionamento com o público em geral, criando condições especiais para incrementar os aspectos simbólicos dos produtos. Por exemplo, investindo na criação e no uso de rótulos diferenciados para definirem as edições limitadas. Em síntese, o produto permanece o mesmo, mas sua embalagem apresenta alterações temporárias, assinalando a edição especial (o que é mais comum com relação a datas ou períodos comemorativos, sejam relacionados à cultura do produto ou ao contexto sócio comercial). 
Há edições limitadas comemorativas da própria história do produto e da empresa fabricante ou edições especiais de datas e eventos nacionais e mundiais. Além disso, também são realizadas mesclas simbólicas. Por exemplo, em nome das fábricas e dos seus produtos, gestores patrocinam times de futebol ou eventos culturais, relacionando à produção um conjunto diversificado de afetos e valores simbólicos. Tudo isso pode ainda ser incrementado com a oferta de brindes, associando o produto a outros produtos assessórios que são os brindes. Esses produtos-brinde caracterizam eventos publicitários de curto ou médio prazo, cujas séries limitadas atiçam o interesse de colecionadores. Enfim, a adoção de recursos e os investimentos na dinâmica da indústria cultural recorrem também à valorização de produtos acessórios e banais (Figura 5).

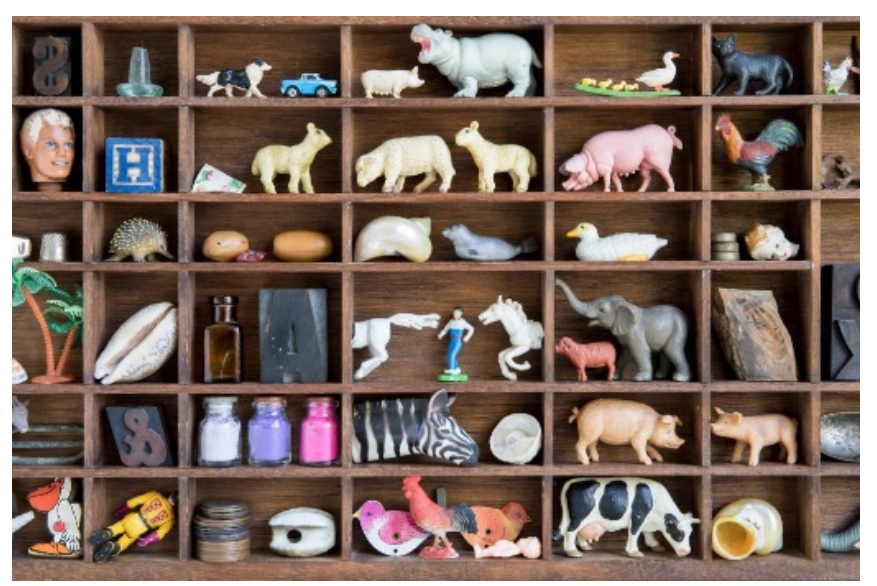

Figura 5. Um gabinete de banalidades com produtos industriais.

Fonte da imagem: https://super.abril.com.br/comportamento/colecoes/

Para Sêga (2010, p. 62), com o apoio da mídia de massa, a dinâmica da indústria cultural "transforma arquétipos em estereótipos, estandartizando padrões de moda por meio da repetição desses modelos até serem consumidos massivamente pela sociedade". Assim como houve a denúncia sobre a perda da "aura" artística na reprodução técnica (BENJAMIN, 1980), posteriormente, Abraham Moles (1975) denunciou o engodo industrial na produção de objetos kitsch, como simulacros ou imitações decadentes da estética artístico-artesanal.

Tecnicamente, a denúncia de Moles foi superada porque atualmente a tecnologia digital controla sofisticados aparelhos mecânicos como impressoras de objetos tridimensionais, resultando em simulações eficientes de quase tudo que já foi projetado. Mas, antes disso, a presença massiva dos produtos kitsch nas atividades cotidianas já havia superado o ideal estético artístico-artesanal, com a imposição de outros padrões para o gosto popular. Na segunda metade do século XX, o resultado do investimento comunicativo na cultura industrial foi parcialmente criticado e apoiado por diferentes teóricos, como foi descrito no clássico estudo, "Apocalípticos e Integrados", de Umberto Eco (1984).

Por sua vez, Sêga (2010, p. 58) confirma a sedução e a consolidação do produto kitsch ao assinalar que "a satisfação em ter aquele objeto, mesmo sabendo muitas vezes que se trata de uma imitação, torna-se imensa por ele estar próximo ao objeto real". Isso é ainda reforçado pela necessidade de identificação cultural, uma vez que "com a aquisição desse objeto, o indivíduo percebe que estabeleceu uma relação de aproximação e de interação entre ele e a sociedade de consumo ou sociedade de massa". O resultado é o auto reconhecimento do próprio indivíduo, como parte da cultura de consumo, porque "a relação de aproximação acaba adquirindo uma característica real para o seu usuário ao notar que estabeleceu uma aproximação consigo mesmo". 
Em síntese, consumidores ou usuários são envolvidos desde cedo na fantasmagoria dos produtos que, seguidamente, é recomposta no momento da percepção, com a recordação de histórias e eventos. Isso afeta sobremaneira a dinâmica psicossocial de colecionadores ou colecionadoras e "as coisas que colecionam têm um significado especial e são de facto uma força cativante e poderosa" (HARGREAVES, 2014, p. 2). Mas, comumente, isso também influencia, por empatia, a percepção e imaginação dos observadores. Assim, foi constituído e desenvolvido em âmbito mundial o complexo mercado do colecionismo, em função da ampla diversidade de coleções, incluindo os produtos industriais aparentemente "banais".

Enfim, até poucas décadas atrás, viveu-se o apogeu da cultura industrial, com o desenvolvimento e a consolidação da "indústria cultural". O colecionismo de produtos industriais foi e ainda é alimentado na relação entre estético-simbólica entre indústria e cultura. Atualmente, há o domínio da cultura digital. Mas, compor, contar e ilustrar histórias em suportes digitais ou materiais ainda continua atual. Por isso, além da necessidade funcional, há a constante valorização dos aspectos estético-simbólicos de Design, na dinâmica persistente e fortalecida da "indústria cultural", sempre renovada em associação com as áreas de Publicidade e Branding, entre outras.

\section{Considerações finais}

Como parte da memória coletiva, reunindo pessoas de diferentes gerações por meio do uso de produtos e serviços no ambiente familiar e nos espaços de convivência sociocultural, a vigência cultural dos produtos industriais ultrapassa sua dimensão utilitária. Além dos produtos seriados como selos, moedas e outros, que são percebidos com mais relevância por sua função sociopolítica e econômica, os produtos industriais aparentemente "banais" também são apreciados e selecionados, na composição de coleções institucionais e particulares. Entre outras possibilidades, isso resulta na preservação e no reconhecimento da influência da área de Design na cultura industrial e, consequentemente, na "indústria cultural".

Independentemente da condição socioeconômica de seus habitantes, uma residência no século XIX era predominantemente ocupada por móveis, objetos e utensílios artesanais ou artísticos. A dinâmica cotidiana também era dominada por produtos e serviços caseiros. Mas, nas décadas do século XX, progressivamente, houve a ocupação dos espaços e da dinâmica familiar e social com produtos industrializados. Os serviços também passaram a ser realizados com o uso desses produtos. Assim, a produção industrial, resultante direta dos projetos de Design, dominou a sensorialidade, a vida, a afetividade e o imaginário das pessoas de diversas gerações.

A partir da metade do século XX, o domínio estético-simbólico da produção industrial foi expresso na arte, principalmente no movimento PopArt. Mas, independentemente, o imaginário coletivo e as relações socioculturais já eram dominadas pela forma e o conteúdo estético-simbólico da cultura industrial. Isso evidenciado no culto aos produtos industrializados que, inclusive, é manifesto no colecionismo das peças fabricadas nas indústrias e, principalmente, nos acervos de produtos aparentemente "banais". É necessário reconsiderar a aparente banalidade dos produtos, porque caso fossem verdadeiramente banais não haveria o interesse em cultuá-los e colecioná-los.

Para além da motivação pessoal e compulsiva que mobiliza o colecionismo, sobre os produtos aparentemente "banais", foi assinalado neste artigo o processo de estético-simbólico de ocupação cultural, que é psicológico, subjetivo e intersubjetivo, devido ao convívio continuado das pessoas com sua presença. Isso define os produtos como registros socioculturais e também pessoais ou familiares. Aliás, a potente influência cultural do cotidiano, marcado pela produção industrial, não passou desapercebida pelos teóricos frankfurtianos e, muito menos, pelos profissionais de Publicidade que, continuamente, incrementaram a dinâmica ideológico-publicitária da "indústria cultural". 
A área de Publicidade e os recursos de Marketing e Branding, contudo, não configuram diretamente os elementos e os aspectos estético-simbólicos nos corpos dos produtos de uso, consumo ou comunicação. O potencial estético-simbólico dos produtos decorre diretamente do seu formato, incluindo configuração e volumes; da expressividade dos materiais, como densidade, textura, cor e tonalidade; da dinâmica perceptível de sua funcionalidade e, tudo isso, é considerado e formalizado nos projetos de Design.

As estratégias de Marketing e Branding e as ações comunicativas de Publicidade associam os produtos e serviços a diversas situações e discursos. Mas, tudo isso é diretamente representado pela corporeidade dos produtos. Inclusive, os elementos de identificação e os instrumentos ou equipamentos de realização dos serviços são produtos que, em grande parte, são fabricados nas indústrias.

Em síntese, a área de Design, por meio dos projetos desenvolvidos por designers, formaliza e orienta a fabricação dos produtos que, com sua fisicalidade, realizam a mediação sensorial entre o público de consumidores, clientes e usuários e a ideologia institucionalmente proposta com estratégias de Marketing, Branding e ações de comunicação publicitária. Em grande parte, a percepção dos serviços também decorre da expressão física dos produtos e seus efeitos. Por isso, deve haver coerência entre o que é comunicado e o esteticamente vivenciado e simbolicamente associado na relação direta com os produtos. Enfim, a potencialidade dos produtos e atuarem como registros memoráveis das ideias comunicadas e das experiências vivenciadas é especialmente confirmada no culto aos produtos evidenciado no colecionismo.

\section{Design, Industrial Modernity and Collecting}

Abstract: This article presents part of a qualitative research about Design products in Collecting culture. The research made with (1) an exploratory stage to search sources and (2) another bibliographic stage to identify and select concepts, theoretical arrangements and information on the topic has the general objective to show the cultural influence of industrial products as a motivation for collecting. Such phenomenon results from the aesthetic-symbolic domain of Design in the daily life of several generations of people in the 20th and 21st centuries. The cultural relevance of industrial products it is especially noted in the collections of apparently "banal" and low-cost products. Beyond to its socio-historical aspects, subjective, intersubjective and socio-cultural motivations are also considered in the context of modern Western culture. In summary: the main result of this research is to point out that the symbolic-social value of industrial products, mainly those apparently "banal" is directly associated with the formal and functional qualities defined in the Design projects as it is especially highlighted in collecting.

Keywords: Collecting products; Market Society; Industrial Culture

\section{Referências Bibliográficas}

ANDREOZI, Lucila "Para matar a curiosidade": possível história do design. Disponível em http://www.faap.br/museu/setor-educativo-propostas-e-pesquisas/historia-design.asp Acessado em 08/08/2020

BENJAMIN, Walter. A obra de arte na época de sua reprodutibilidade técnica. Coleção Os Pensadores, São Paulo, Editora Abril Cultural, 1980.

BENJAMIN, Walter. O colecionador. In Passagens. São Paulo: Imprensa Oficial, 2009. 
CAMARGO, Téa. Colecionismo, Ciência e Império. Universidade Federal do Paraná - Centro de Documentação e pesquisa de História e Domínios Portugueses - CNPQ 2012.

CHANEY, D. The department store as a cultural form. Theory, Culture \& Society. January, vol. $1, \mathrm{n}$. 3, p. 22-31, EUA, 1983.

ECO, Umberto. Apocalípticos e Integrados. Ed. Lumen; Lisboa, 1984.

HARGREAVES, Manuela. Colecionismo e colecionadores: um olhar sobra a história da arte na $2^{a}$ metade do século XX. In: Conferência sobre "Colecionismo e Mercados de Arte". Fundação Cupertino de Miranda; Faculdade de Letras Universidade do Porto, 2014.

HORKHEIMER, Max \& ADORNO, Theodor. A indústria cultural: o iluminismo como mistificação de massas. Pp. 169 a 214. In: LIMA, Luiz Costa. Teoria da cultura de massa. São Paulo: Paz e Terra, 2002.

INFOPÉDIA. Cultura Material. Porto: Porto Editora, 2003-2020. [consult. 2020-08-08 Disponível na Internet: https://www.infopedia.pt/\$cultura-material

INFOPEDIA. Enciclopédia e Dicionários Porto Editora: Cultura Material. Disponível em: Acesso em: $08 / 08 / 2020$

LE GOFF, Jacques. História e Memória. Editora da UNICAMP, Campinas, SP 1990.

MATTAR, Fauze Najib. Pesquisa de marketing: metodologia, planejamento. São Paulo: Atlas, 2005.

MOLES, Abraham. O kitsch. São Paulo: Perspectiva, 1975.

MUSAS - Revista Brasileira de Museus e Museologia, n. 3, 2007. Rio de Janeiro: Instituto do Patrimônio Histórico e Artístico Nacional, Departamento de Museus e Centros Culturais.

NARLOCH, Leandro. Coleções: passatempo ou obsessão? (2004) Disponível em https://super.abril.com.br/comportamento/colecoes/. Acessado em 31/03/2020.

PERASSI, Richard. A visualidade das marcas institucionais e comerciais como campo de significação. São Paulo: PUC/SP, 2001.

PERASSI, Richard. Mídia do Conhecimento. Florianópolis, SC: SIGMO/UFSC, 2019.

POMIAN, Krzysztof. La Culture de la Curiosité. Le temps de la réflexion. Paris: Gallimard, 1983.

POMIAN, Krzysztof. Colecção. In Enciclopédia Einaudi. Porto: Imprensa Nacional, 1984.

SÊGA, Christina Maria Pedrazza. - Revista Signos do Consumo. V.2, N.1, 2010.

SUDJIC, Deyan. A Linguagem das Coisas. Editora Intrínseca. Rio de Janeiro, 1a Edição, 2010.

VALENTIM, Marta L. P. Métodos qualitativos de pesquisa em ciência da informação. São Paulo: Polis, 2005.

WICK, Rainer. Pedagogia da Bauhaus. São Paulo: Martins Fontes, 1989. 